\title{
Óleo Essencial de Alho (Allium sativum) como Antimicrobiano Frente a Cepas ATCC de Escherichia coli (25922) e Staphylococcus Aureus (25923).
}

Isadora N. Oliveira, Gustavo O. Everton, Anna Clara C. Ferreira, lure B. de Sousa, Adenilde N. Mouchrek, Amanda M. Teles \& Victor E. M. Filho

Óleo essencial de alho (Allium sativum) como cepas ATCC frente antimicrobiana Escherichia coli (25922) e Staphylococcus aureus (25923). Por milhares de anos, o Allium sativum e seus extratos foram usados para tratar infecções. Assim, este trabalho teve como objetivo avaliar a atividade antimicrobiana através da determinação da concentração inibitória mínima (CIM) do óleo essencial de alho (Allium sativum) frente às cepas de Escherichia coli e Staphylococcus aureus. Foram obtidos para Escherichia coli o CIM de $25 \mu \mathrm{g} / \mathrm{mL}$ e $100 \mu \mathrm{g} / \mathrm{mL}$ de Staphylococcus aureus. A partir dos resultados obtidos neste estudo pode-se concluir que o óleo apresentou uma atividade bactericida eficaz contra as cepas padrão de Staphylococcus aureus e Escherichia coli. Resultados semelhantes foram observados na literatura.

Palavras Chave: Óleo; Alho; Antimicrobiana.

Essential oil of garlic (Allium sativum) as ATCC strains front antimicrobial Escherichia coli (25922) and Staphylococcus aureus (25923). For thousands of years the Allium sativum and its extracts have been used to treat infections. Thus, this study aimed to evaluate antimicrobial activity by determining the minimum inhibitory concentration (MIC) of the essential oil of garlic (Allium sativum) front of the strains of Escherichia coli and Staphylococcus aureus. It was obtained for Escherichia coli the CIM of $25 \mu \mathrm{g} /$ $\mathrm{mL}$ and $100 \mu \mathrm{g} / \mathrm{mL}$ Staphylococcus aureus. From the results obtained in this study it can be concluded that the oil presented an effective bactericidal activity against the standard strains of Staphylococcus aureus and Escherichia coli. Similar results were observed in the literature.

Keywords: Oil; Garlic; antimicrobial. 


\section{Introdução}

Há milhares de anos o Allium sativum e seus extratos têm sido usados para tratar infecções. A maior concentração de fitoquímicos terapêuticos encontra-se nos bulbilhos. Centenas de fitoquímicos bioativos foram identificados sendo os de maior destaque os compostos sulfurados, presentes em quantidades três vezes maiores do que em outros vegetais como a cebola e o brócolis ${ }^{1}$.

Allium sativum é uma planta herbácea, caracterizada por um bulbo (cabeça) dividido em dentes (bulbilhos). É um alimento funcional rico em alicina que possui ação antiviral, antifúngica e antibiótica, tem também, considerável teor de selênio agindo como antioxidante. Alguns compostos sulfurados presentes no alho possuem atividade hipotensora, hipoglicemiante, hipocolesterolêmica e antiagregante plaquetária, reduzindo o risco de doenças cardiovasculares. As demais substâncias encontradas no alho possuem atividade imunoestimulatória e antineoplásica².

No Brasil, o uso de plantas medicinais passa de geração à geração, baseando-se na prática indígena, influenciada pelas culturas africana e portuguesa. Desde a implantação do Sistema Único de Saúde (SUS), na década de 1980, o governo estimula o uso dos recursos naturais para a promoção da saúde através de tecnologias eficazes, visando a integração do ser humano com o meio ambiente e a sociedade ${ }^{3}$.

Dessa forma, este estudo teve por objetivo avaliar a atividade antimicrobiana por determinação da concentração inibitória mínima (CIM) do óleo essencial de alho frente a cepas de Escherichia coli (ATCC 25922) e Staphylococcus aureus (ATCC 25923).

\section{Metodologia}

O presente trabalho foi desenvolvido no Laboratório de Físico-Química e Laboratório de Microbiologia do Programa de Controle de Qualidade de Alimentos e Água do Pavilhão Tecnológico da Universidade Federal do Maranhão (UFMA).

\section{OBTENÇÃO DO ÓLEO ESSENCIAL}

Os dentes de alho foram coletados no município de São
Luís-MA, Brasil, em março de 2017 e transportadas para o Laboratório de Físico-Química de Alimentos do Pavilhão Tecnológico da Universidade Federal do Maranhão (UFMA), onde foram secas em temperatura ambiente, trituradas (em pó) e armazenadas para extração do óleo essencial.

Para extração do óleo essencial dos dentes de Allium sativum (alho), utilizou-se um extrator de Clevenger, de vidro acoplado a um balão de fundo redondo de $1000 \mathrm{~mL}$ acondicionado em manta elétrica como fonte geradora de calor. A cada rotina de extração do óleo essencial foram pesadas $100 \mathrm{~g}$ das folhas e adicionou-se agua destilada na proporção de 1:10 e colocadas em um balão de fundo redondo acoplado ao sistema extrator. A hidrodestilação foi conduzida a $100^{\circ} \mathrm{C}$ por $5 \mathrm{~h}$ recolhendo-se o óleo essencial extraído. O óleo foi seco por meio de percloração com $\mathrm{Na}_{2} \mathrm{SO}_{4}$. Essas operações foram realizadas em triplicatas e as amostras armazenadas em ampolas de vidro âmbar sob refrigeração de $4^{\circ} \mathrm{C}$ para evitar possíveis perdas de constituintes voláteis. Posteriormente submetido as análises.

\section{MICRO-ORGANISMOS TESTADOS}

Foram utilizadas duas cepas de bactérias provenientes da "American Type Culture Collection" (ATCC) doadas pelo Laboratório de Microbiologia do Controle de Qualidade de Alimentos e Água da Universidade Federal do Maranhão (PCQA-UFMA), sendo uma Gram-negativas: Escherichia coli (ATCC 25922) e uma Gram-positiva: Staphylococcus aureus (ATCC 25923). A identificação das cepas foi confirmada pelo uso de ensaios bioquímicos, seguindo as recomendações do manual de microbiologia clínica ${ }^{4}$.

\section{PADRONIZAÇÃO DO INOCULO}

Culturas microbianas puras mantidas em ágar TSA foram repicadas para caldo de infusão de cérebro e coração (BHI) e incubadas a $35^{\circ} \mathrm{C}$ até atingirem fase exponencial de crescimento (4-6h). Após esse período, as culturas tiveram sua densidade celular ajustada em solução salina 0,85\% estéril, de modo a se obter uma turbidez comparável à da solução padrão de McFarland 0,5 , o que resulta em 
uma suspensão microbiana contendo aproximadamente $1,5 \times 108 \mathrm{UFC} / \mathrm{mL}$ de acordo com as normas do Clinical and Laboratory Standards Institute ${ }^{5}$.

\section{CONCENTRAÇÃO INIBITÓRIA MÍNIMA}

Para determinação da concentração inibitória mínima (CIM), utilizou-se a técnica de diluição em caldo. Preparou-se uma solução, utilizando-se DMSO 2\%, na concentração de $1000 \mu \mathrm{g} / \mathrm{mL}$ do óleo essencial de Allium sativum. Em seguida foram realizadas diluições seriadas em caldo Mueller Hinton (MH), resultando nas concentrações de 1000, 500, 250, 200, 100, 50 e $25 \mathrm{~mL}$. A suspensão microbiana, realizada previamente de acordo com as normas do Clinical and Laboratory Standards Institute ${ }^{5}$, contendo 1,5x108 UFC/mL das cepas foram adicionadas a cada concentração. Realizouse o controle constituído apenas da solução de DMSO nas mesmas concentrações testadas. Foram reservados tubos para controle de esterilidade do caldo e de crescimento bacteriano. Logo após os tubos foram incubados a $35^{\circ} \mathrm{C}$ por 24 horas.

Logo após os tubos foram incubados a $35^{\circ} \mathrm{C}$ por 24 horas. Após o período de incubação, foi verificada a concentração inibitória mínima do óleo, sendo definida como a menor concentração que visivelmente inibiu o crescimento bacteriano (ausência de turvação visível). Ensaios realizados em triplicata.

\section{Resultados e Discussão}

Através dos resultados obtidos, observou-se que o óleo essencial de alho possui atividade antimicrobiana frente à Escherichia coli e Staphylococcus aureus. Pela determinação da concentração inibitória mínima (CIM), foi obtida para Escherichia coli a CIM de $25 \mu \mathrm{g} / \mathrm{mL}$ e para Staphylococcus aureus $100 \mu \mathrm{g} / \mathrm{mL}$, conforme a Tabela 1 .

Dormans e Deans ${ }^{6}$, após utilizarem óleos essenciais de orégano, gerânio, cravo e pimenta, frente a 25 espécies Gram-positivas e negativas e observaram que bactérias Gram-positivas eram mais suscetíveis que as Gramnegativas.
Resultados semelhantes foram encontrados por Indu et. al. $^{7}$ que ao analisarem a atividade antimicrobiana do óleo essencial de alho relataram que o mesmo apresentou atividade antibacteriana excelente em todas as concentrações testadas $(100,75 \%, 50 \%$ e 25$)$ a diferentes cepas de Escherichia coli.

Tabela 1. Concentrações $\mu \mathrm{g} / \mathrm{mL}$ testadas do óleo essencial frente aos micro-organismos.

\begin{tabular}{|c|c|c|c|c|c|c|c|}
\hline \multirow{2}{*}{$\begin{array}{c}\text { Bactéria } \\
\left(1,5^{*} 108 \text { UFC/mL) }\right.\end{array}$} & \multicolumn{6}{|c|}{ Concentração $(\mu \mathrm{g} / \mathrm{mL})$} \\
\cline { 2 - 8 } & 500 & 250 & 200 & 100 & 50 & 25 & 5 \\
\hline Escherichia coli & - & - & - & - & - & - & + \\
\hline $\begin{array}{c}\text { Staphylococcus } \\
\text { aureus }\end{array}$ & - & - & - & - & + & + & + \\
\hline
\end{tabular}

Nota: (-) Ausência de turvação visível / Impedimento do crescimento microbiano/ (+) Turvação visível / Crescimento microbiano

Observou-se também que a atividade mais eficiente do óleo essencial se mostrou frente à Escherichia coli, em uma diferença de CIM $100 \mu \mathrm{g} / \mathrm{mL}$ maior para Staphylococcus aureus.

Para Nascimento et al. ${ }^{8}$, os métodos de atividade antimicrobiana (diluição e difusão) não são necessariamente comparáveis. Isto por que o método de diluição mostra ser o que melhor disponibiliza dados quantitativos, enquanto a difusão em placa constitui-se um método qualitativo.

\section{Conclusões}

A partir dos resultados obtidos neste estudo pode-se concluir que o óleo essencial extraído dos dentes de alho apresentou uma eficiente atividade bactericida frente às cepas padrão de Staphylococcus aureus e Escherichia coli. Obtiveram-se resultados semelhantes ao da literatura.

\section{Agradecimentos AO PCQA e à UFMA}




\section{Referências Bibliográficas}

1. Cutler, R.R.; Wilson, P. Antibacterial activity of a new, stable, aqueous extract of allicin against methicillinresistant Staphylococcus aureus. British journal of biomedical Science, v. 61, n.2, p.71-4, 2004.

2. Corzo-Martínez, M. et al. Biological properties of onions and garlic. Trends in Food Science \& Technology, v.18, n.12, p.609-25, 2007

3. Almeida, M. Z. Plantas medicinais. 3. ed. Salvador: EDUFBA, 2011.

4. Murray, P. R. Microbiologia Clínica. Guanabara Koogan, 2003. 2v.

5. Clinical and Laboratory Standards Institute. Performance standards for antimicrobial disk susceptibility tests. Approved standard. M2A8, 8.ed. 2003.

6. Dorman, H.; Deans, S. Antimicrobial agents from plants: antibacterial activity of plant volatile oils. J Applied Microbiology, Reino Unido, v. 88, n. 2, p. 308- 16, feb. 2000.

7. Indu, M. N.; Hatha, A. A. M.; Abirosh, C.; Harsha, U.; Vivekanandan, G. Antimicrobial activity of some of the South-Indian spices against serotypes of Escherichia coli, Salmonella, Listeria monocytogenes and Aeromonas hydrophila. Brazilian Journal of Microbiology, São Paulo, v. 37, n. 2, p. 153-158, apr./jun. 2006

8. Nascimento, P. F. C. et al. Atividade antimicrobiana dos óleos essenciais: uma abordagem multifatorial dos métodos. Revista Brasileira de Farmacognosia, v.17, p. 108-113, 2007. Disponível em: $<$ http://www.scielo.br/pdf/rbfar/v17n1/a20v17n1.pdf $>$. Acesso em: 01 ago. 2017.

\section{Isadora N. Oliveira, Gustavo O. Everton*, Anna Clara C. Ferreira, lure B. de Sousa, Adenilde N. Mouchrek, Amanda M. Teles \& Victor E. M. Filho}

Universidade Federal do Maranhão, Departamento de Tecnologia Química, Laboratório de Pesquisa e Aplicação de Óleo Essenciais, CEP 65080-805, São Luís, MA, Brasil.

"E-mail: gustavooliveiraeverton@gmail.com 